\title{
Crime Preparation Regulation Peculiarities in Criminal Codes of CIS Countries
}

\author{
${ }^{1}$ Sergej N. Bezugly, ${ }^{2}$ Viktoriya S. Kirilenko, ${ }^{3}$ Anzhelika I. Lyahkova, ${ }^{4}$ Leonid A. Prokhorov \\ ${ }^{5}$ Oksana S. Stepanyuk \\ 1,3,5 Belgorod State University, 85 Pobedy Street, Belgorod, Belgorod Region, 308015, Russia \\ ${ }^{2}$ The Institute of Service Sector and Entrepreneurship (Branch) of DSTU in Shakhty, 147 Shevchenko Street, \\ Shakhty, Rostov Oblast, 346500, Russia \\ ${ }^{4}$ Kuban State University, 149 Stavropol'skaya St., Krasnodar, Russia \\ Email:bezugly@bsu.edu.ru
}

Received: 16 $^{\text {th }}$ May 2018, Accepted: 04 ${ }^{\text {th }}$ June 2018, Published: 30 ${ }^{\text {th }}$ June $_{2018}$

\begin{abstract}
The article analyzes the texts of CIS country criminal laws for the completeness of objective and subjective reflection of crime preparation signs. They revealed the specifics of methods for objective characteristics description in the articles of the General Part of the Criminal Law. They studied the legislative approaches to the limits and the methods of preparatory action criminalizing. It is stated that with all the diversity of legislative approaches to objective and subjective crime preparation sign formalizing, it is possible to single out some common features for all states.
\end{abstract}

Keywords: Incomplete Crime, Preparation for a Crime, Objective Side, Subjective Side, Criminalization Ways, Criminalization Limits.

\section{Introduction}

A clear description of a criminal-legal prohibition follows from the very definition of legality principle. The quality of the criminal law is determined to some extent depending on the accuracy of regulated criminal relation reflection by criminal law.

The development of a universal approach to the determination of the actions that constitute the preparation for a crime is one of particular problems for criminal law both in the field of legislation and in the doctrine of criminal law [5].

The studies of an unfinished crime and, in particular, the preparation for a crime is implemented in several directions: as one of the foundations for a crime prevention [6], as one of the components of sociological research subject [3], as well as in other directions.

There are also the studies touching on the problems of responsibility or punishment for "an accidentally unfinished crime" [7], the reasons for a crime performance impossibility $[10 ; 2]$.

With all the diversity of approaches to the study of an unfinished crime, there are practically no developments concerning the preparation for a crime. It should be noted that the preparation for a crime and an offense attempt should be regarded as independent criminal-legal phenomena, although they are the types of an unfinished crime, since they have a different set of objective and subjective attributes and entail different consequences. Proceeding from this, it seems reasonable to study the preparation for a crime first.

\section{Methodology}

The research was based on a dialectical approach to the disclosure of legal phenomena and processes using general scientific (system, logical, analysis and synthesis) and private-scientific methods. The latter includes formal-legal, linguistic-legal and comparative-legal one, which were collectively used to study the texts of the criminal laws of 11 post-Soviet countries in order to identify the features of objective and subjective sign reflection in the criminal law norms concerning the preparation for a crime. The choice of this group is conditioned by the commonness of the previous historical development of criminal legislation within the USSR and an equal period of post-Soviet development. This makes it possible to predict the presence of common features of preparation record as a type of unfinished crime, on the one hand, and as the diversity in the formulation of individual provisions relating to the completeness of objective and subjective features, as well as the limits and methods of criminalization, on the other.

\section{Results and Discussion}

The analysis of CIS countries criminal legislation allows to conclude that the legislators of all countries have not abandoned the record for the notions of preparation to a crime and an attempted crime in the General Part of the criminal law of the country. The tendency to distinguish these types of crime dates back to the pre-revolutionary period of criminal legislation development and was adopted by the criminal laws of the USSR.

All criminal codes of the CIS countries contain the description of objective and subjective signs of preparation for a crime, but with their varying completeness. The Art. 32 of the Criminal Code of the Republic of Tajikistan [4] describes the preparation of 
a crime as a deliberate finding, the fabrication or adaptation of crime means or tools by a person, the finding of crime accomplices, the collusion to commit a crime or other deliberate creation of conditions for a crime commission, if the crime was not completed due to circumstances beyond a person's power. The definition contains the subjective aspect of the preparatory actions, consisting in the deliberate form of a guilt.

There are six types of acts described in the law that form the composition of the preparation:

- The search for means or tools (the receipt of means or tools from anywhere, either lawfully or illegally);

- The manufacture of means or tools (the creation or the production of means or tools in any way);

- The adaptation of means or tools by a person (the change of an existing object without a major change of its design while maintaining its original design);

- The search for crime accomplices (any actions to involve persons in a crime);

- The conspiracy to commit a crime (reaching an agreement between two or more persons on the joint commission of a crime);

- Other deliberate creation of conditions for a crime commission. The wording "other deliberate creation of conditions for a crime commission" is an appraisal concept and is subject to broad interpretation. A similar action determining the preparation is contained in RF Criminal Code [4], only the subjective signs of the first five forms of preparation are not determined. The Criminal Code of the Republic of Azerbaijan [4] also contains the indicated signs of preparation, except for the act in the form of means or tools manufacture. The Criminal Code of the Republic of Moldova [4] does not contain a sign of preparation in the form of associate finding.

The Criminal Code of the Republic of Kazakhstan [4] contains all objective attributes, but also indicates a direct intent in the preparation norm. In general, the issue of the subjective aspect remains unresolved both in a number of legislative acts and in the doctrine of criminal law. Almost all the codes refer to "other deliberate creation of conditions" and only from this formulation one can conclude about the guilt form of all preparatory actions. It is important to note that there is neither harm to an object, nor purposeful actions encroaching on this object, and there is no desire to cause damage to this object in the absence of a direct intent $[8$, p. 110].

The Criminal Code of the Kyrgyz Republic [4] contains the indication of an intentional form of guilt in the norm of preparation, and also contains all the acts listed in the above-mentioned codes, except of one - "the making of means or tools." A legislator of Turkmenistan did not record one of the alternative actions that make up the composition of the preparation - the search for accomplices in his standard on preparation for a crime.

The Criminal Code of the Republic of Belarus [4] defines the preparation through two alternative acts the search or adaptation of means or tools, while mentioning a deliberate creation of other conditions. The Armenian Criminal Code [4] contains identical objective signs of preparation and also determines an intentional form of a guilt.

There are also the options for a preparation norm record, containing fully valued concepts. The Art. 25 of the Republic of Uzbekistan Criminal Code [4] presents the following wording of the preparation standard: "An act of a person that creates the conditions for an intentional crime commission or concealment interrupted before its commencement under the circumstances beyond his control is recognized as the preparation for a crime." There are no specific objective signs in the norm, which allows an extensive interpretation of the norm. An absolute universality of the norm is among the merits of this approach. The definition of an attempt has also the description of an act, which creates the conditions for an intentional crime concealment, which is not presented in any of CIS country Criminal Code.

The Criminal Code of Ukraine [4] contains a rather unusual act for the criminal legislation of CIS, which forms the composition of the preparation - "the removal of obstacles".

The CIS criminal codes contain various lists of objective features that make up the composition of the preparation, but absolutely all of them are in the article regulating the preparation for a crime and they do not indicate the possibility of making a preparation for a crime by inaction. The doctrine of criminal law recognizes the possibility of preparation for a crime by inaction [9, p. 93].

Preparation is punishable only when a crime was not brought to an end due to the circumstances beyond the control of a person responsible. The analysis of the criminal codes allows us to conclude that the reasons for the failure of a crime are fully described in two versions: independent of a perpetrator's will (Republic of Kazakhstan, Kyrgyz Republic and Republic of Moldova) and the circumstances beyond a person's control (all other codes containing an indication of failure to complete a crime). The sign of criminal activity interruption is compulsory and it forms the composition for a crime preparation together with the performed actions.

Obviously, it is necessary to take into account the sign of criminal activity interruption in the norm of preparation for a crime. However, the criminal codes of the Republic of Belarus and Ukraine do not contain this feature, only the acts are described forming the composition of the preparation for a crime. Since it is 
impossible to ascertain the presence of the composition without this sign, it seems that the practice of law enforcement in these countries has worked out the legal problem solution.

Under the criminal codes of CIS countries, the preparation for a crime is punishable, but the range of criminalized preparations as well as the way of criminalization are not homogeneous.

Almost all the criminal laws of CIS countries in the norm of preparation for a crime contain the indication of preparation punishability for certain categories or classifications of crimes.

The most common is the criminalization of preparation for grave and especially grave crimes, which is typical for the Republic of Azerbaijan, Armenia, the Kyrgyz Republic, the Republic of Kazakhstan, the Republic of Tajikistan and Russian Federation. The remaining criminal laws provide for the responsibility for the preparation to other categories of crimes:

- The Criminal Code of the Republic of Moldova - the crimes of moderate severity, grave, especially grave, extremely grave crimes.

- The Criminal Code of the Republic of Belarus - all categories, except for the crimes that do not pose a great public danger.

- The Criminal Code of Turkmenistan - the crimes of medium gravity, grave and especially grave crimes.

- The Criminal Code of Ukraine - all categories of crimes, except for small gravity crimes.

If the limits of preparation criminalization are directly related to the categories of crimes, which leads to the lack of uniformity within the limits of criminalization, the methods of criminalization are identical in all countries, except of two ones.

In this regard, the Criminal Code of the Republic of Uzbekistan draws attention, as it does not contain any restrictions for crime categories in the norm on the preparation of crimes. The only sign that characterizes the punishment of preparation is the indication of a crime guilt intentional form, to which a perpetrator is being prepared. It can be concluded that in this case the preparation for a crime is criminalized according to a general rule. This approach has two sides. On the one hand, there may be an unreasonable expansion of criminal repression, however, it can be leveled by the institution of an act insignificance; on the other hand, it can be concluded that a legislator did not neglect the preparation of certain categories of crimes from the field of criminal legal relations. After all, it happens that a person, when preparing for a single crime, can commit a qualitatively different crime characterized by greater severity later.
Preparation is partially criminalized in the Criminal Code of the Republic of Kazakhstan. Criminal liability is provided for the preparation to a grave or an especially grave crime, and the revolutionary rule on the general punishability of preparation for terrorist crimes is recorded by CIS legislation. The responsibility for a terrorist crime preparation and attempt is established regardless of a category [1].

Analyzing the abovementioned innovation, we can conclude that by the elimination of categorization sign during the determination of the punishability for a terrorist crime preparation, the state anti-terrorist strategy is realized to some extent. It is quite obvious that this provision is the manifestation of the criminal policy in this sphere.

This approach seems to be very convenient. If there is an objective need to expand criminal responsibility for certain relations, a legislator should make changes only in preparation norm, without changing the provisions of the Criminal Law Special Part.

\section{Conclusions}

The existence of a standard on the preparation for a crime is typical for all criminal codes of CIS countries, however, a set of signs that allow to qualify a person's actions as preparatory ones, vary in some cases.

Most criminal laws attempted to describe the objective signs characteristic / typical of an act that forms the preparation composition in as much detail as possible. Estimating concepts that allow a broad interpretation of the preparation norm are contained in all the criminal codes of CIS countries, which makes it possible to make the norm more universal and effective one.

During the determination of the subjective characteristics, you can see that in some cases an intentional form of guilt is defined directly, in other cases the deliberate form of guilt follows from the norm sense. It seems possible to conclude that all laws provide only an intentional form of guilt in preparation composition.

The limits of punishability, that is, the criminalization of preparation, are found in all criminal laws. In most cases, this happens through the recognition of preparation for certain categories (classifications) of crimes as a punishable one.

The methods of criminalization are characterized by heterogeneity of approaches. In some cases, the preparation for certain categories (classifications) of crimes is recognized as punishable, in other cases it is recognized as punishable by defining the punishability of preparation for a particular crime kind or type. 


\section{References}

[1] Agybayeva L. A. In line with innovations // Juridical newspaper. - 2014. - 04 sent. (in Russian)

[2] Chen Jia lin (2000) New Ideas about Impossibility of Crime // JOURNAL OF THE NATIONAL PROCURATORS COLLEGE. 2000-01.

[3] Gregory M. Herek. (2008) Hate Crimes and Stigma-Related Experiences Among Sexual Minority Adults in the United States // Journal of Interpersonal Violence. 2008.

[4] http://base.spinform.ru/index.fwx (accessed 20 March 2018).

[5] John S. Strahorn. (1939) Preparation for Crime as a Criminal Attempt // Wash. \& Lee L. Rev. (1939-1940). V1.

[6] Kingsbury A.A. (1973) Introduction to security and crime prevention surveys. 1973.

[7] Margit E. Oswald (2006) Punitive Reactions to Completed Crimes Versus Accidentally Uncompleted Crimes // Journal of Applied Social Psychology. 2006.

[8] Rarog A. I. Subjective aspect and the qualification of crimes. - M., 2001. - 134 p. (in Russian)

[9] The criminal law. Experience in theoretical modeling. / G. Z. Anashkin, S. V. Borodin, I. M. Galperin et al.; Ed. in charge: S. G. Kelina, V. N. Kudryavtsev. - M.: Nauka, 1987. -276 p. (in Russian)

[10]ZHAO Bing-zhi (2008) On Issues of Legal Impossibility and Attempted Crime due to Impossibility // Northern Legal Science. 2008-01. 